\title{
The environmental awareness of secondary school students in Hanoi
}

\author{
Nhận thức về môi truờng của học sinh Trung học Co sở tại Hà Nội \\ Research article
}

Giap, Binh Nga*

Faculty of Education and Psychology, Hanoi National University of Education, Hanoi, Vietnam

\begin{abstract}
This article reports on a study of secondary school students in Hanoi. The author surveyed approximately 500 students from a sample of 10 secondary schools to assess levels of environmental awareness including environmental knowing, concerning and applying. Independent variables included region of school, and the gender of students. Although there are no region and gender differences in environmental awareness, the mediating relationships are found.
\end{abstract}

Báo cáo đề cập kết quả nghiên cứu nhận thức của học sinh trung học cơ sở về khía canh môi truờng trong các nhà truòng tại Hà Nội. Tác giả đã tiến hành khảo sát 500 em học sinh tù 10 truò̀ng trung học co sở để đánh giá mức độ nhận thức về môi trường bao gồm các biến số: hiểu biết, vấn đề liên quan và áp dụng. Các biến số độc lập bao gồm khu vực và giới tính. Mặc dù không có sụ khác biệt về khu vực và giới tính trong nhận thức về môi truờng, mói quan hệ điều hòa giữa các biến số được phát hiện.

Keywords: Awareness, variables, environmental education, knowing, concerning, applying

\section{Introduction}

In this study, the environmental awareness of students in Hanoi's secondary schools is evaluated, as measured by students' environmental knowing, concerning and applying. Hanoi capital is similar to many other cities in that it has an environmental education policy of voluntary infusion in secondary school (Giap B.N, 2014). It may be argued that Hanoi capital is paradigmatic of national environmental education policy. In fact, environmental education is not as important or as rigorous as traditional courses of study and educational leaders neglected to address environmental education. For that reasons, the environmental awareness of students is investigated. The purpose of this research was to measure environmental knowing, concerning and applying in secondary students. The author hypothesized that the students' environmental knowing would be lower in comparison to other variables. Further, the patterns of interrelationship among variables are tested.

\section{Materials and methods}

\subsection{Materials}

The author designed a questionnaire to be answered by secondary students in Hanoi. This questionnaire sought (a) demographic information about the respondent; (b) the student's awareness of environmental issues including environmental knowing, concerning and applying. The questionnaire contained 17 Likert-type 5 points scale questions. The author pretested the original version on several classes and removed, relocated, or revised questions that were too easy or difficult. Most students completed the questionnaire in about 25 minutes.

\subsection{Methods}

To best understand and interpret the data, a series of indexes was developed. These indexes grouped questions by type of knowledge or information. The questions were derived from topics covered in textbooks and real life.

Concerning Score: Likert-type items asking if a respondent agrees or disagrees with a statement concerning the degree of environmental problems; 7 items sought levels of concerning about the environment. Summary scores could range from a high of 35 to a low of 7 .

Knowing Score: Six other Likert-type items measuring levels of knowing about the environment. Summary scores could range from a high of 30 to a low of 6 . 
Applying Score: Four other Likert-type items measuring levels of applying the environmental knowledge in school. Summary scores could range from a high of 20 to a low of 4.

The questionnaire was administered in 10 secondary schools; 500 students participated in the survey. To counteract potential bias, author stratified the sample by drawing on both city and suburban schools. He did this to evaluate whether the community or the type of school influenced students' knowing and concerning about the environment. The sample showed broad demographic variation. Among respondents, 68\% were female and 31\% were male. Fifty-one percent grew up primarily in the city, $48 \%$ in the suburban. The data is analysed by using SPSS and AMOS version 23.

\section{Results and discussion}

\subsection{Results}

\subsubsection{Factor analysis}

Assuming that identifying latent variables that account for the correlations among measured variables is the goal of the research. As researchers, author decided to use the structural equation modelling analysis (Gefen, D. et all, $2000)$ in this research. Both exploratory factor analysis (EFA) and confirmatory factor analysis (CFA) are used. The model tested was a relatively simple model with 3 latent factors (Concerning, Knowing, Applying) and 17 measured variables. Correlations and descriptive statistics for the factors are presented in the table below (Table 1).

Table 1. Means, standard deviations, and correlations

\begin{tabular}{lrrrcr} 
Factors & Mean & SD & $\mathbf{1}$ & $\mathbf{2}$ & $\mathbf{3}$ \\
\hline 1. Concerning & 3.83 & 0.73 & & \\
2. Knowing & 3.31 & 0.95 & $0.64^{* *}$ & & \\
3. Applying & 3.71 & 0.85 & $0.57^{* *}$ & $0.62^{* *}$ &
\end{tabular}

${ }^{* *}$ Correlation is significant at the 0.01 level (2-tailed). $N=500$

As indicated in the Table 1, Knowing score is lower in comparison to other variables: Concerning and Applying. In other words, Concerning and Applying levels were significantly higher than Knowing levels. The mean level of Concerning was 3.83; for Knowing, 3.31; and for Applying, 3.71. There are no region and gender differences in environmental awareness of the secondary students.

As the correlations in Table 1 shows, Concerning was positively correlated with each of the other factors. The correlations ranged from a low of 0.57 to a high of 0.64 . The correlation between Knowing and Applying was 0.62. This indicates that when the Knowing quality was good, students tend to apply it to the reality.

\subsubsection{Mediating relationships}

The important point for mediating relationship is that a third variable plays an important role in governing the relationship between two other variables. Baron and Kenny
(2009) argued that for us to claim a mediating relationship, we need to first show that there is a significant relationship in the direct pathway between the independent variable (Knowing) and the dependent variable (Applying).

\section{Direct pathway}

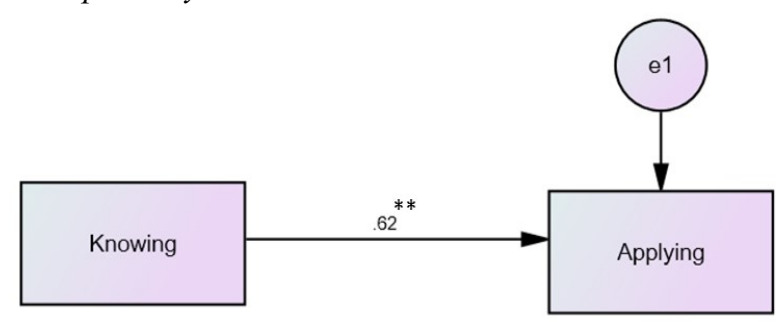

Figure 1. The relationship between Knowing and Applying. ** $p<0.01$

The regression coefficient for the direct pathway Knowing on Applying is 0.62 . In this case, it is also correlation between Knowing and Applying.

\section{Indirect pathway}

The next step is to show that there is a significant relationship between the independent variable and the mediator (Concerning). Then we need to show that there is a significant relationship between the mediator and the dependent variable.

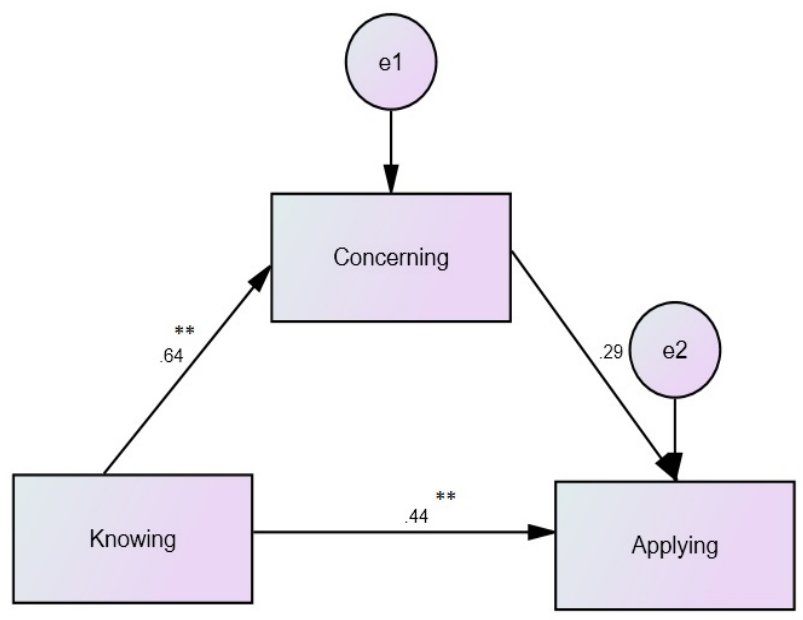

Figure 2. Mediating role of Concerning in explaining the relation between Knowing and Applying ** $p<0.01$

The regression coefficient for the direct path Knowing on Concerning is 0.64 , whereas the regression coefficient for the direct path Concerning on Applying is 0.29. Then the regression coefficient for the indirect path Knowing on Applying as product of single paths: $0.64 \times 0.29=0.20$. If Knowing changes by one standard deviation, then Applying changes by 0.20 standard deviations via Concerning. The total path as product of sum up direct path and indirect path: $0.44+0.20=0.64$.

These three conditions require that the three paths (involving Concerning, Applying, and Knowing) are all individually significant. The final step consists of demonstrating that when the mediator and the independent variable are used simultaneously to predict the dependent variable, the 
previously significant path between the independent and dependent variables is now greatly reduced (partially mediating relationship), if not nonsignificant.

\subsection{Discussion}

The data revealed that Hanoi secondary students are well aware of and concerned about environmental problems but have weak substantive knowing about environment. These students would like to have more environmental instruction, which they also believe will be useful for their future life.

It is believed that effective environmental education must be offered in a required course. An appropriate environmental education curriculum should have the following features:

- It should be multidisciplinary, drawing relevant knowledge from both the natural and social sciences as well as humanities.

- It should involve learning basic concepts so that students will not make errors in analysis. Students must learn to integrate materials and think holistically (Milbrath, 1989).

- It should be problem oriented and should address environmental problems that students encounter in their daily lives.

- It should involve value clarification and moral reasoning in discussions about problems so that students can better understand various actors in environmental controversies and can clarify their own values (Hausbeck, et all, 1992).
- It should address both local environmental issues and global environmental problems.

\section{Conclusions}

This research indicates that environmental awareness of secondary students in Hanoi is quite high. The environmental knowing is low among them, but their levels of environmental concerning and applying are higher. There are no region and gender differences in environmental awareness. The effect of knowing on applying is partially mediated by concerning.

\section{References}

[1] Giap, B. N. (2014). "Education for environment: A useful concept.". J. Viet. Env. 6(3), 188-190.

[2] Gefen, D., Straub, D., \& Boudreau, M. C. (2000). Structural equation modeling and regression: Guidelines for research practice. Communications of the association for information systems, 4(1), 7.

[3] Hayes, A. F. (2009). Beyond Baron and Kenny: Statistical mediation analysis in the new millennium. Communication monographs, 76(4), 408-420.

[4] Milbrath, L. W. (1989). Envisioning a sustainable society: Learning our way out. Albany: SUNY Press.

[5] Hausbeck, K. W., Milbrath, L. W., \& Enright, S. M. (1992). Environmental knowledge, awareness and concern among 11th-grade students: New York State. The Journal of Environmental Education, 24(1), 27-34. 